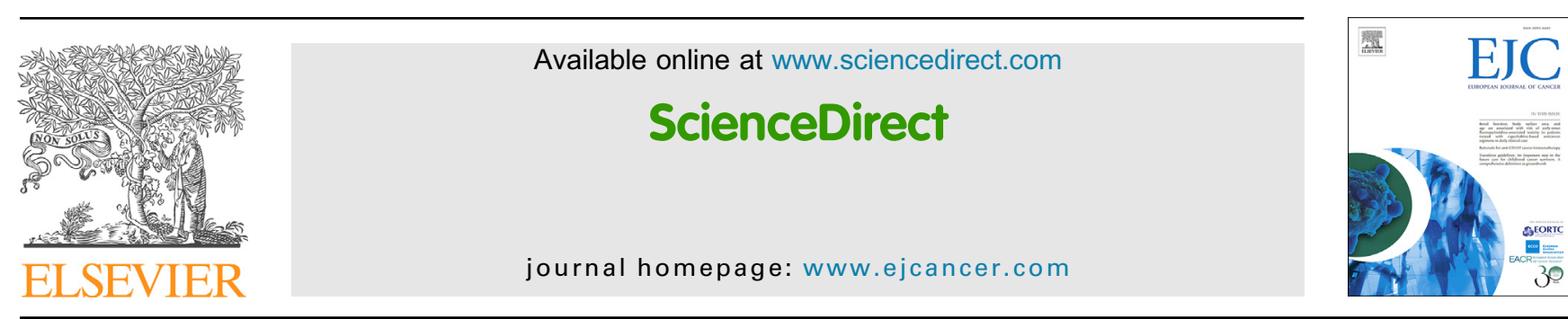

Original Research

\title{
Neuroblastoma messenger RNA is frequently detected in bone marrow at diagnosis of localised neuroblastoma patients
}

\author{
Esther M. van Wezel ${ }^{\mathrm{a}, \mathrm{e}}$, Boris Decarolis ${ }^{\mathrm{b}}$, Janine Stutterheim ${ }^{\mathrm{a}, \mathrm{e}}$, \\ Lily Zappeij-Kannegieter ${ }^{\mathrm{a}}$, Frank Berthold ${ }^{\mathrm{b}}$, \\ Roswitha Schumacher-Kuckelkorn ${ }^{b}$, Thorsten Simon ${ }^{b}$, Marta Fiocco ${ }^{c}$, \\ Max M. van Noesel ${ }^{\text {d,f }}$, Huib N. Caron ${ }^{\mathrm{e}}$, C. Ellen van der Schoot ${ }^{\mathrm{a}}$, \\ Barbara Hero ${ }^{\mathrm{b}}$, Godelieve A.M. Tytgat ${ }^{\mathrm{e}, \mathrm{f}, *}$
}

\footnotetext{
${ }^{a}$ Department of Experimental Immunohematology, Sanquin Research and Landsteiner Laboratory of the AMC,

University of Amsterdam, Amsterdam, The Netherlands

${ }^{\mathrm{b}}$ Children's Hospital, University of Cologne, Pediatric Hematology and Oncology, Germany

${ }^{\mathrm{c}}$ Department of Biostatistics, Leiden University Medical Center and Dutch Childhood Oncology Group, The Hague,

The Netherlands

'Department of Pediatric Oncology, Sophia Children's Hospital, Erasmus Medical Center, Rotterdam, The Netherlands

e Department of Pediatric Oncology, Emma Children's Hospital, Academic Medical Center, University of Amsterdam,

The Netherlands

${ }^{\mathrm{f}}$ Prinses Máxima Centrum, Utrecht, The Netherlands
}

Received 31 May 2015; received in revised form 25 September 2015; accepted 9 November 2015

Available online 12 January 2016

\section{KEYWORDS}

Neuroblastoma;

Bone marrow;

Localised;

Minimal disease;

Real-time quantitative PCR

\begin{abstract}
Introduction: The clinical importance of the detection of neuroblastoma messenger RNA (mRNA) in bone marrow (BM) of localised neuroblastoma patients at diagnosis remains unclear. In this prospective multicentre study, BM samples of a large cohort, were studied using real-time quantitative polymerase chain reaction (qPCR).

Methods: BM samples at diagnosis from 160 patients with localised neuroblastoma were prospectively collected at Dutch and German centres between 2009 and 2013. qPCR was performed using five neuroblastoma specific markers. The association with other biological factors and the prognostic impact of BM positivity and clinical response was assessed.

Results: In 58 out of 160 patients neuroblastoma mRNA was detected in BM. In 47 of the 58 positive samples only one marker was found positive. BM positivity was significantly associated
\end{abstract}

\footnotetext{
* Corresponding author: Department of Pediatric Oncology, Academic Medical Center, University of Amsterdam, Meibergdreef 9 , 1105 AZ, Amsterdam, The Netherlands. Tel.: +31 205663050.

E-mail address: g.a.tytgat@amc.uva.nl (G.A.M. Tytgat).
} 
with MYCN amplification $(p=0.02)$ and deletion of chromosome $1 p(p=0.04)$. In total 31 patients had an event, of which only five patients had progression to stage IV. BM positivity was not associated with an unfavourable outcome. However, the detection of more than one marker was associated with an unfavourable outcome (systemic or local relapse) (event free survival $48 \%$ versus $85 \% ; \mathrm{p}=0.03$ ) in the whole cohort and in the observation group.

Conclusions: BM positivity was associated with unfavourable biological factors and might represent more aggressive tumours. Patients with qPCR positive BM should not be upstaged, because of very few systemic events in the cohort. However, for patients with more than one marker positive a more careful follow-up is advisable. These results need to be verified in a very large cohort of localised patients.

(c) 2015 Elsevier Ltd. All rights reserved.

\section{Introduction}

Neuroblastoma is an extracranial solid tumour of childhood [1,2]. The presence of metastatic spread at diagnosis is the most important factor in determining outcome $[3,4]$. Localised patients (stage I, II and III) have a good prognosis, but a small percentage of these patients can relapse.

According to the International Neuroblastoma Risk Group, bone marrow (BM) disease is determined by morphology on smears and biopsies [5]. However, realtime quantitative polymerase chain reaction (qPCR) and immunocytology are more sensitive techniques for the detection of minimal neuroblastoma cells than morphology [6-9].

Detection of GD2 positive tumour cells in BM samples of localised patients is suggested to be correlated with an unfavourable outcome [10]. Neuroblastoma messenger RNA (mRNA) detection by qPCR in localised neuroblastoma has been described in a very small number of patients ( 4 out of 14 patients) by Shono et al. [11]. Corrias et al. [12] have studied BM of 126 localised patients in a retrospective study by using qPCR. No significant association between tyrosine hydroxylase (TH) expression and outcome was observed, however detection of GD2 synthase was surprisingly associated with a favourable outcome. Yanez et al. studied 94 BM samples and 81 blood samples of localised patients by using TH and Doublecortin as markers. Detection of these markers in BM was not associated with a poor survival. However, detection of TH and Doublecortin in blood was predictive of relapse [13]. These results suggest that the clinical importance of neuroblastoma mRNA detection in BM at diagnosis of localised patients remains unclear. Therefore, the goal of our study was to investigate the frequency and prognostic value of the detection of a panel of five sensitive and specific mRNA markers (paired-likehomeobox2B [PHOX2B], dopa decarboxylase [DDC], tyrosine hydroxylase [TH], cholinergic receptor alpha 3 [CHRNA3], growth-associated protein 43 [GAP43]) [9,14-19] in BM from localised neuroblastoma patients. Our group has recently demonstrated the superiority of this panel compared to the use of single markers [9].

\section{Methods}

\subsection{Patients and treatment}

In this study BM samples at diagnosis were taken from children diagnosed with localised neuroblastoma between 2009 and 2013. Histologic diagnosis of neuroblastoma was established and centrally confirmed for all patients. Staging was done according to the International Neuroblastoma Staging System (INSS) [4,20]. Patients were treated according to the similar protocols of the German NB2004 trial and the Dutch DCOG09 trial. Based on the risk stratification (Supplemental Fig. 1) patients were assigned to the observation, medium or high risk group. In the observation group patients underwent initial surgery and were then observed for 12 months or until the end of the second year of life. Local progression or threatening symptoms were treated with N4 chemotherapy. In the medium risk protocol treatment consisted of alternating $\mathrm{N} 5$ and $\mathrm{N} 6$ courses, four N7 courses and retinoic acid for 12 months. In the high risk protocol treatment consisted of two $\mathrm{N} 8$ courses (if randomised to, German patients), alternating N5 and N6 courses (three each), Metaiodobenzylguanidine (MIBG) therapy and high dose chemotherapy with autologous stem cell transplantation followed by retinoic acid for 12 months.

For therapy stratification, the status of the MYCN oncogene and the status of distal chromosome $1 \mathrm{p}(1 \mathrm{p} 36)$ were investigated using two different molecular techniques (for MYCN: FISH, Southern Blot or arraybased comparative genomic hybridisation and for $1 \mathrm{p}$ deletion: FISH, PCR or array-based CGH) in the DCOG and GPOH reference laboratories. The test result for each parameter was given according to the criteria of the European Neuroblastoma Pathology, Biology, and Bone Marrow Group. [21]

The GD2 immunocytology of BM samples was done according to the internationally standardised protocol described by Swartz et al. 2005. For all Dutch and 
German patients this was performed in Cologne, Germany [22].

Written informed consent from parents or guardians was obtained for all patients. The study was approved by the Medical Research Ethics Committee of the Academic Medical Center (Amsterdam, the Netherlands) and the University of Cologne (Cologne, Germany). Also ethical approval was acquired from all participating hospitals locally.

\subsection{RNA extraction, reverse transcription and real-time quantitative PCR}

Whole BM RNA was isolated from PAX blood RNA tubes according to the instructions of the manufacturer (Qiagen, Venlo, the Netherlands) with the PAX blood RNA Kit. Complementary DNA (cDNA) was synthesised from $2-3 \mu \mathrm{g}$ of RNA, using $25 \mu \mathrm{mol} / 1 \mathrm{random}$ hexamers (Invitrogen, Carlsbad, CA, United States of America [USA]), $1 \mathrm{mmol} / 1 \mathrm{dNTPs}$ (Promega, Madison, WI, USA) and $100 \mathrm{U}$ of MMLV transcriptase (Invitrogen), in a total reaction volume of $20 \mu \mathrm{l}$ and incubated at $42^{\circ} \mathrm{C}$ for $45 \mathrm{~min}$. Finally, the reverse transcriptase was inactivated by heating and the volume was diluted to $100 \mu \mathrm{l}$. qPCR for PHOX2B, TH, DDC, CHRNA3 and GAP43 was performed using beta-glucuronidase (used for normalisation) on the Step-One-Plus (Applied Biosystems, Carlsbad, CA, USA). Primer and probe sequences have been described previously [9]. Reactions were carried out in $20 \mu \mathrm{l}(10 \mu \mathrm{l}$ Taqman Fast Universal PCR Mastermix (Applied Biosystems), $0.8 \mu \mathrm{l}$ of $7.5 \mu \mathrm{M}$ forward and reverse primer and $0.8 \mu \mathrm{l}$ of $5 \mu \mathrm{M}$ probe and $5 \mu \mathrm{cDNA}$. Initial heating was done for $20 \mathrm{~s}$ at $95^{\circ} \mathrm{C}$, followed by 50 cycles of $1 \mathrm{~s}$ at $95^{\circ} \mathrm{C}$ and $20 \mathrm{~s}$ at $60^{\circ} \mathrm{C}$. All qPCR experiments were carried out in triplicate and mean values were used. If more than one sample of a patient was available, samples were tested separately. In case of discrepant results, the positive sample was used in the analysis.

\subsection{Data analysis}

A sample was scored positive if one out of five markers was above the threshold for positivity as has been described previously [10]. In short, PHOX2B was scored positive if the $\mathrm{Ct}$ value of the sample was $<50$ and the other markers were scored positive if the $\Delta \mathrm{Ct}$ of the sample was $>3 \mathrm{Ct}$ than the $\Delta \mathrm{Ct}$ found in control $\mathrm{BM}$ samples. The quantitative range was defined as described by van Velden et al. 2007 [23]. To calculate the level of infiltration, the expression level of the RNA PCR targets were related to the expression level in neuroblastoma cell line IMR32, according to the following formula: $2^{\Delta \Delta \mathrm{Ct}}(\mathrm{dCt}$ IMR32- $\mathrm{dCt} \mathrm{BM}) \times$ $100 \%$. To study the association between qPCR positivity and other biological factors Fisher's exact test was used. Survival rates were estimated by employing Kaplan-Meier's methodology. To assess the significant differences between the estimated survival curves the log-rank test has been used. The median follow-up was assessed by the reverse Kaplan-Meier method. All statistical analyses were performed by using SPSS version 21.

\section{Results}

\subsection{Patient characteristics}

One hundred sixty localised patients were included in the study (39 stage I, 61 stage II and 57 stage III; Table 1). Patient age ranged from 0 to $6215 \mathrm{~d}$, with a median of $423 \mathrm{~d}$. An estimated 5-year overall survival and event free survival of $94 \%( \pm 2)$ and $80 \%( \pm 3.7)$, respectively, was observed. The median follow-up after diagnosis was 32 months (range 2.7-79.5).

Most patients (123/160) were treated according to the observation protocol of the GPOH NB04/DCOG NB09 protocol.

Table 1

Patients characteristics

\begin{tabular}{|c|c|c|}
\hline \multicolumn{3}{|l|}{ Age (d) } \\
\hline Median (range) & & $423(0-6215)$ \\
\hline$<12$ months & $68 / 160(43 \%)$ & \\
\hline \multicolumn{3}{|l|}{ Country } \\
\hline Netherlands & $24 / 160(15 \%)$ & \\
\hline Germany & $136 / 160(85 \%)$ & \\
\hline \multicolumn{3}{|l|}{ INSS stage } \\
\hline Stage 1 & $39 / 160(24 \%)$ & \\
\hline Stage 2 & $61 / 160(38 \%)$ & \\
\hline Stage 3 & $57 / 160(36 \%)$ & \\
\hline Multilocular & $2 / 160(1 \%)$ & \\
\hline Localised but stage unknown & $1 / 160(1 \%)$ & \\
\hline \multicolumn{3}{|l|}{ Risk group } \\
\hline Observation group & $123 / 160(77 \%)$ & \\
\hline Medium risk group & $22 / 160(14 \%)$ & \\
\hline High risk group & $15 / 160(9 \%)$ & \\
\hline \multicolumn{3}{|l|}{ MYCN } \\
\hline Amplification & $15 / 160(9 \%)$ & \\
\hline No amplification & $144 / 160(90 \%)$ & \\
\hline Not analysed/ unknown & $1 / 160(1 \%)$ & \\
\hline \multicolumn{3}{|l|}{ Loss of heterozygosity $1 \mathrm{p}$} \\
\hline $1 \mathrm{p}$ normal & $112 / 160(70 \%)$ & \\
\hline 1p aberration & $34 / 160(21 \%)$ & \\
\hline Not analysed/ unknown & $14 / 160(9 \%)$ & \\
\hline \multicolumn{3}{|l|}{ Treatment observation group } \\
\hline Observation & $29 / 123(24 \%)$ & \\
\hline Complete resection & $52 / 123(42 \%)$ & \\
\hline Partial resection & $10 / 123(8 \%)$ & \\
\hline Chemotherapy & $32 / 123(26 \%)$ & \\
\hline \multicolumn{3}{|l|}{ Survival (years) } \\
\hline Mean event free survival $( \pm \mathrm{SE})$ & & $5.2( \pm 0.2)$ \\
\hline 5-years event free survival $( \pm \mathrm{SE})$ & & $77 \%( \pm 3.7)$ \\
\hline Mean overall survival $( \pm \mathrm{SE})$ & & $6.2( \pm 0.1)$ \\
\hline 5-years overall survival $( \pm \mathrm{SE})$ & & $94 \%( \pm 2.0)$ \\
\hline \multicolumn{3}{|l|}{ Observation time (months) } \\
\hline Median (range) & & $32(2.7-79.5)$ \\
\hline
\end{tabular}

INSS, International Neuroblastoma Staging System; SE, standard error; EFS, event free survival; OS, overall survival. 


\subsection{Detection of neuroblastoma $m R N A$ in $B M$ samples}

In $58 / 160$ patients $(36 \%)$ neuroblastoma mRNA was detected in $\mathrm{BM}$ at diagnosis. In 47 of the 58 positive samples $(83 \%)$ only one marker was positive (Fig. 1A). This indicates a very low level of infiltration. PHOX2B was most often positive $(46 / 58 ; 79 \%)$, whereas TH and DDC were only positive in five samples $(9 \%)$. In 11 patients $(27 \%)$ more than one marker was detected. In only two patients all five markers showed positive results. Most patients with positive qPCR results had very low levels of infiltration (Fig. 1B). In 10 patients a level of infiltration of more than 0.01 percent was observed. In most of these patients $(8 / 10)$ more than one marker was positive.

\subsection{Association between $q P C R$ positivity and biological factors}

Detection of neuroblastoma mRNA was not associated with stage and age (Fig. 2A and B). However, there was a significant association between unfavourable biological factors and qPCR positivity (Fig. 2C and D). In 10/ 15 patients $(67 \%)$ with a MYCN amplification qPCR results of the BM were positive, whereas in only 47/144 patients (33\%) with a MYCN single copy positive results were observed $(\mathrm{p}=0.02)$. Furthermore, in $18 / 34$ patients $(53 \%)$ with a $1 \mathrm{p}$ aberration positive qPCR results were observed, whereas in only $36 / 112$ patients $(32 \%)$ with a normal $1 \mathrm{p}$ status minimal disease was detected.

\subsection{Events and $q P C R$ positivity}

In total, $31 / 160$ patients $(19 \%)$ had an event (23 local progression, five progression to stage IV and three patients progression to stage IVs) (Fig. 3A). Treatment after disease progression was limited in 12 children (further observation only, surgical resection, N4 chemotherapy). Eight patients received more intensive chemotherapy. Eleven patients who were initially treated in the high risk group (HRG) or medium risk group (MRG), were treated according to different relapse protocols (Supplemental Table 1).

In patients with an event, neuroblastoma mRNA in $\mathrm{BM}$ at diagnosis was more often detected than in patients without an event, respectively $52 \%(16 / 31)$ versus $32 \%(42 / 129)$. However, this difference was not statistically significant $(\mathrm{p}=0.1)$. For the 31 patients with an event, qPCR results at the time of event were also available for 16 patients. In 10/16 patients (63\%) qPCR results were positive at the time of event (Supplemental Table 2). We also analysed the large observation group separately $(\mathrm{n}=123)$, because in this group qPCR positivity might change clinical intervention, in contrast to the patients who were already treated according to the MRG $(\mathrm{n}=22)$ and the HRG $(\mathrm{n}=15)$. In this group $21 / 123$ patients $(17 \%)$ had an event (15 local progression, three progression to stage IV and three patients progression to stage IVs) (Fig. 3D). There was no difference in qPCR positivity between patients with and without an event, respectively $38 \%$ (8/21) versus

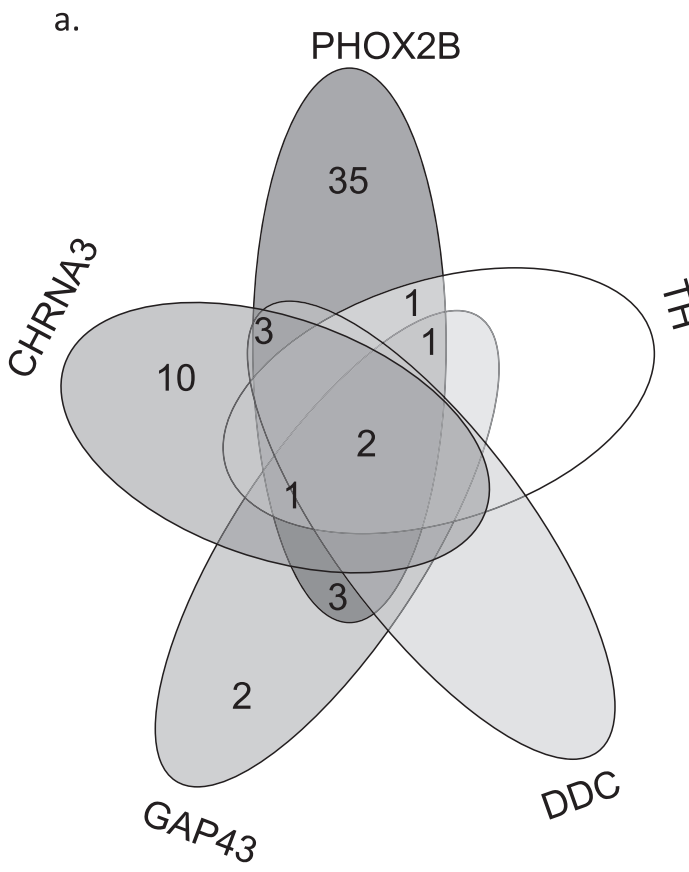

b.

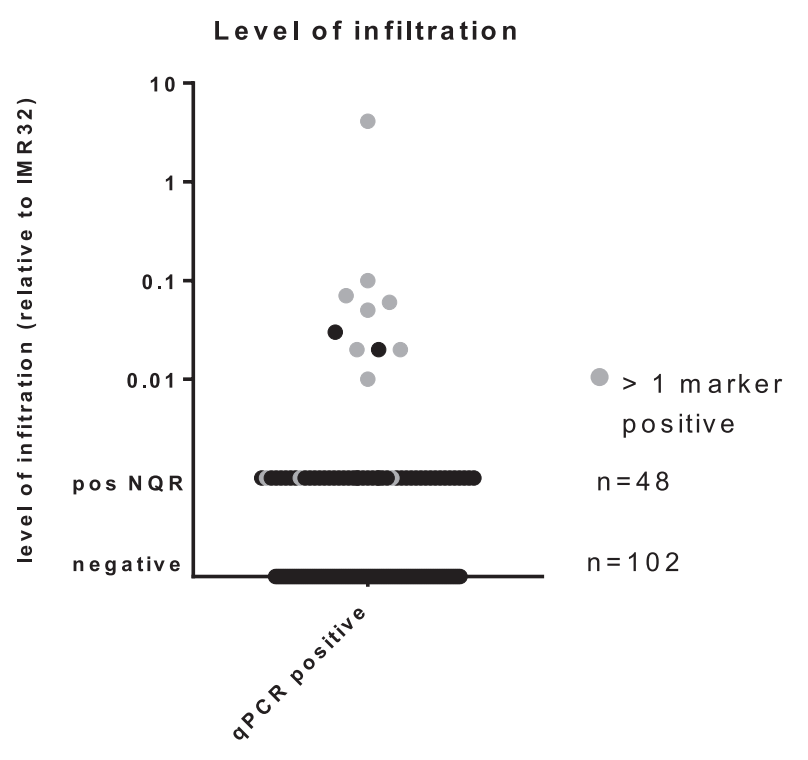

Fig. 1. Marker positivity a. contribution of the different markers to the positive samples. Each ellipse represents positive results of one marker. b. Level of infiltration relative to IMR32. Ten samples were in the quantitative range. In grey the samples with more than one marker positive are indicated. qPCR, quantitative polymerase chain reaction; TH, tyrosine hydroxylase. 


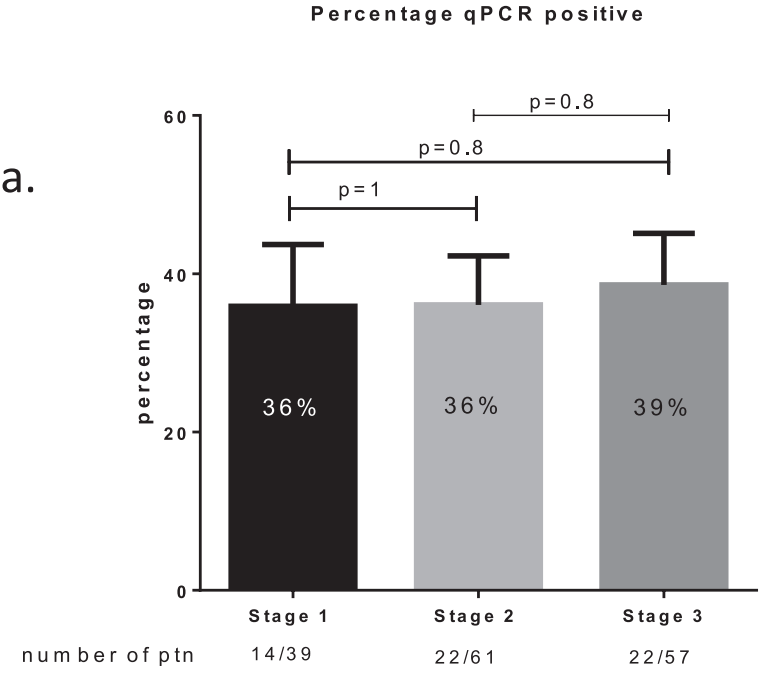

Percentage qPCR positive

C.

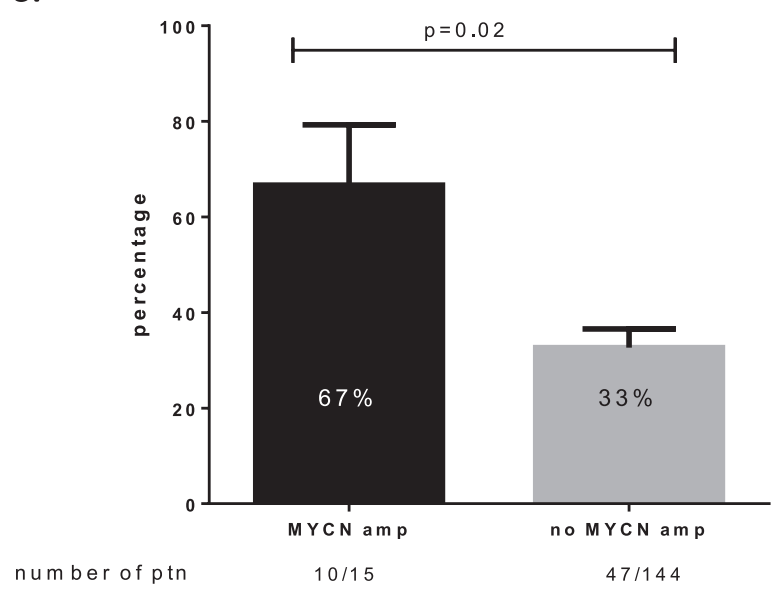

b.

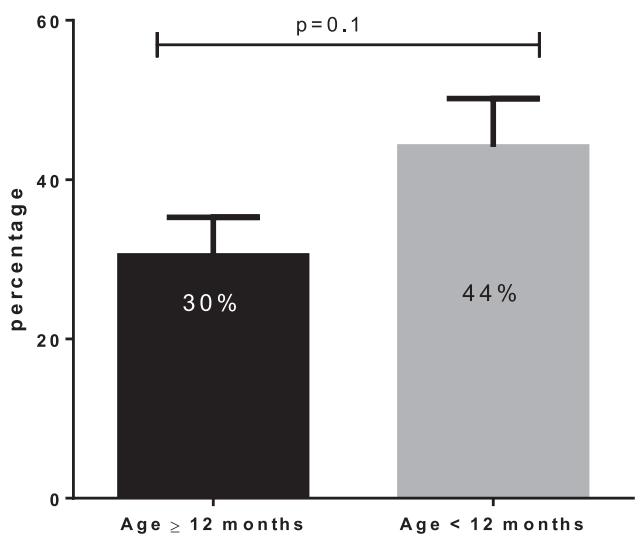

$$
\begin{array}{lll}
\text { number of ptn } & 28 / 92 & 30 / 68
\end{array}
$$

Percentage qPCR positive

d.

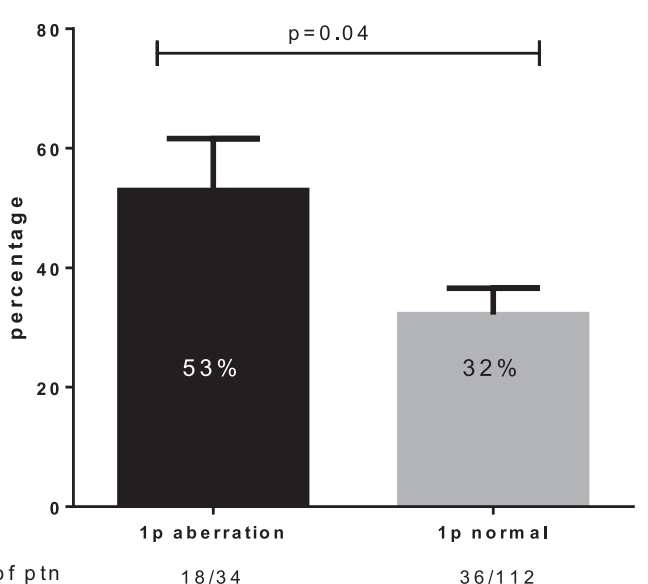

Fig. 2. The percentage of patients with qPCR positive results and known risk factors. a. stage b. age c. MYCN status and d. $1 \mathrm{p}$ status. qPCR, quantitative polymerase chain reaction.

$31 \%(31 / 102)$ (Fig. 3E and 3F). So overall, there was no significant association between qPCR positivity and the number of patients with progressive disease. Furthermore, only very few systemic events occurred in this cohort.

\subsection{Systemic events and BM involvement}

Eight patients developed a systemic event (five progression to stage IV, three progression to stage IVs). Six of these eight patients had qPCR positive BM at diagnosis (three patients with progression to stage IV and all three patients progressing to stage IVs) (Supplemental Table 3). Of the five patients progressing to stage IV, four patients developed BM metastases and one patient developed isolated liver metastases without BM involvement. For three of these patients qPCR results were available at the time of event and in two patients qPCR results were positive at the time of event. Two of the patients progressing to stage IVs developed liver metastases, BM was not assessed at that time. The third patient with progression to stage IVs further progressed to stage IV. This patient developed liver metastases when progressing to stage IVs. BM morphology results were inconclusive at that time point, whereas qPCR results were positive. Progression to stage IV was diagnosed by a distant lymph node metastasis without morphological $\mathrm{BM}$ involvement. In summary, of the eight patients with systemic events four patients had BM disease according to the INSS guidelines at the time of event (three of these four patients had qPCR positive BM at diagnosis).

\subsection{Association between $q P C R$ positivity and event free survival}

Positive qPCR results were not associated with significant impaired event free survival in the whole cohort $(\mathrm{n}=160 ; 5$-year event free survival $70 \%$ versus $81 \%$ 
a.

Events in whole cohort

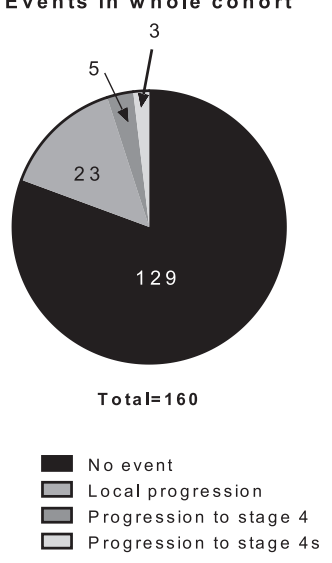

d.

Events in observation group

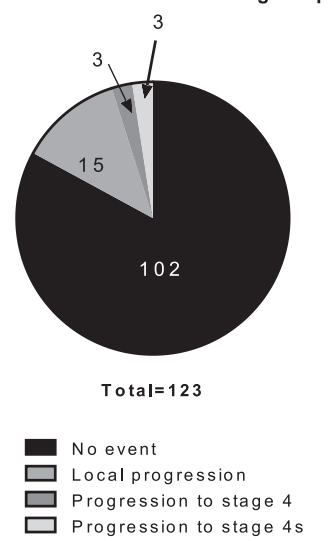

qPCR results in patients with event

b.

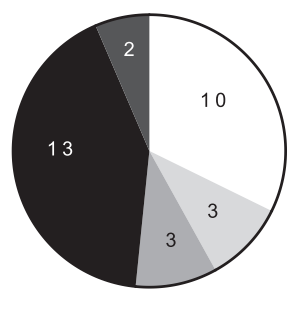

Total $=31$

qPCR pos: local progression

qPCR pos: progression stage 4

qPCR pos: progression stage $4 \mathrm{~s}$

qPCR neg: local progression

qPCR neg: progression stage 4

qPCR results in patients with event in OG

e.

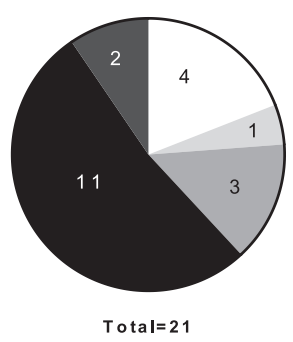

$\square$ qPCR pos: local progression

$\square$ qPCR pos: progression stage 4

$\square$ qPCR pos: progression stage 4s

qPCR neg: local progression

$\square$ qPCR neg: progression stage 4
qPC R results in patients without event

C.

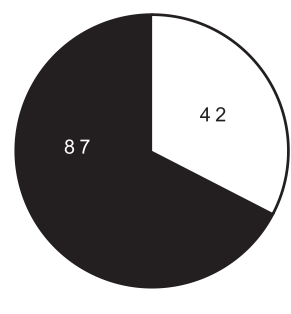

Total=129

$\square$ qPCR positive

qPCR negative
qPCR results in patients without event in OG

f.

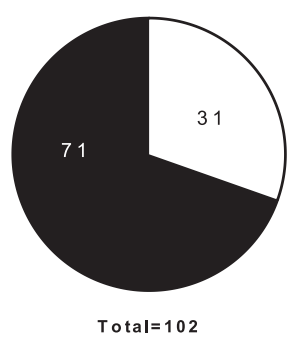

Total $=102$

qPCR positive qPCR negative

Fig. 3. Events and qPCR positivity. a. Number of events in the whole cohort. b. qPCR results in patients with an event in the whole cohort. c. qPCR results in patients without an event in the whole cohort. d. Number of events in the observation group. e. qPCR results in patients with an event in the observation group f. qPCR results in patients without an event in the observation group. qPCR, quantitative polymerase chain reaction.

$\mathrm{p}=0.09)($ Fig. 4A) and in the observation group $(\mathrm{n}=123$; 5-year event free survival $78 \%$ versus $81 \%$ $\mathrm{p}=0.5$ ) (Fig. 4B). Also positive qPCR results for one of the single markers were not associated with significant impaired event free survival in the whole cohort and in the observation group (Supplemental Figs. 2 and 3). However, detection of more than one marker was associated with an unfavourable outcome in the whole cohort (5-year event free survival $55 \%$ versus $79 \%$ $\mathrm{p}=0.03$ ) (Fig. 4C) and the observation group (5year event free survival $56 \%$ versus $82 \% \mathrm{p}=0.03$ ) (Fig. 4D). Five out of 11 patients with more than one marker positive had an event (two local progression, two progression to stage IV and one patients progression to stage IVs and later to stage IV) (Table 2). In four of these five patients GD2 immunocytology results were also positive. One of the patients showing progression to stage IV was already treated according to the high risk protocol. The other patient with progression to stage IV was initially treated according to the observation protocol and underwent partial resection. The patient with progression to stage IVs and subsequently to stage IV was only observed until the progression to stage IV. So overall, detection of more than one marker might identify a small group of patients with an increased risk of tumour progression.

\section{Discussion}

In this large prospective study we have investigated the clinical significance of neuroblastoma mRNA detection by qPCR in patients with localised disease. This is, to our knowledge, the first prospective study addressing this question in a large cohort of neuroblastoma patients with localised disease.

Several studies have shown that localised patients have a good prognosis [24-29] and that local relapse or 
a.

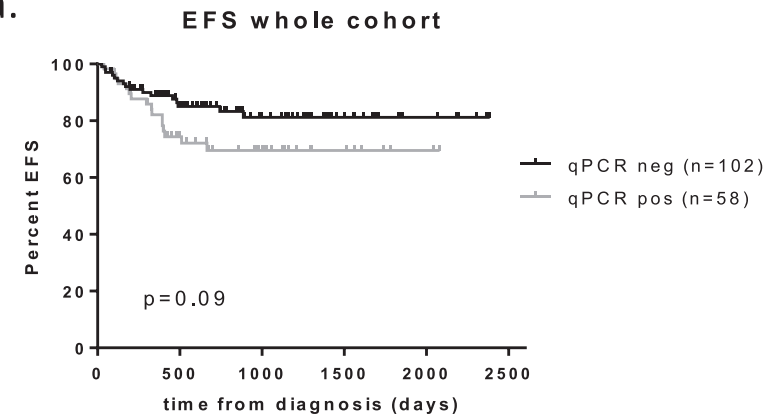

C.

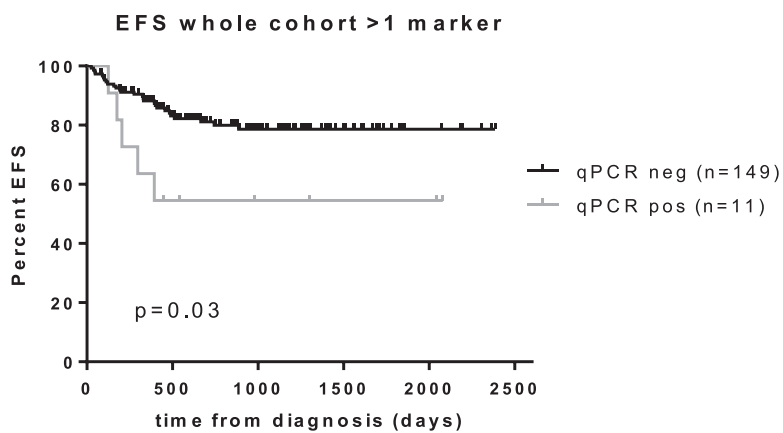

b.

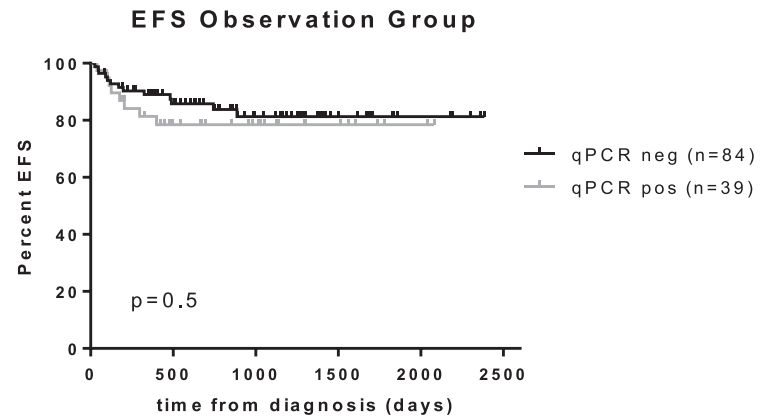

d.

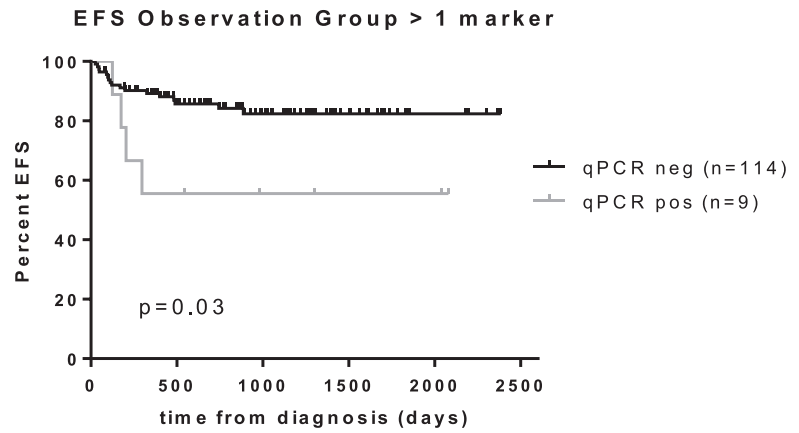

Fig. 4. Event free survival for qPCR positive and negative patients. a. event free survival and qPCR positivity in the whole cohort (grey curve $=\mathrm{qPCR}$ pos; black curve $=\mathrm{qPCR}$ neg). $\mathrm{b}$. event free survival and $\mathrm{qPCR}$ positivity in the observation group (grey curve $=\mathrm{qPCR}$ pos; black curve $=\mathrm{qPCR}$ neg). c. event free survival and qPCR positivity with $>1$ marker in the whole cohort (grey curve $=\mathrm{qPCR}$ pos; black curve $=\mathrm{qPCR}$ neg). . event free survival and $\mathrm{qPCR}$ positivity with $>1$ marker in the observation group (grey curve $=\mathrm{qPCR}$ pos; black curve $=\mathrm{qPCR}$ neg). $\mathrm{qPCR}$, quantitative polymerase chain reaction.

progression is the most common event [30], especially in patients observed without cytotoxic treatment [31]. In our study only five patients $(3 \%)$ showed progression to stage IV (three of these patients had neuroblastoma mRNA detected in BM at diagnosis), and two of these patients were already treated according to the high risk treatment protocol. Furthermore, two patients with a systemic event did not have minimal BM disease at diagnosis. Since very few systemic events occurred and qPCR positivity was much more frequent, localised patients with qPCR positive BM should not be upstaged to stage IV.

Deletion of $1 \mathrm{p} 36$ and $M Y C N$ amplification are the most common chromosomal changes observed in neuroblastoma and are associated with a poor prognosis $[32,33]$. In our study we show that there is a significant

Table 2

Characteristics of the patients with $>1$ marker positive.

\begin{tabular}{|c|c|c|c|c|c|c|c|c|c|c|c|}
\hline Ptn ID & Stage & Risk group & Gender & Age & MYCNA & $\begin{array}{l}1 \mathrm{p} \\
\text { aberration }\end{array}$ & IC & Treatment & Event & Death & $\begin{array}{l}\text { Last } \\
\text { control state }\end{array}$ \\
\hline 1 & 1 & OG & M & 2368 & 0 & 0 & 9 & Complete resection & No & No & $\mathrm{CR}$ \\
\hline 2 & 2 & OG & M & 451 & 0 & 0 & 0 & Complete resection & No & No & $\mathrm{CR}$ \\
\hline 3 & 2 & OG & M & 0 & 0 & 0 & 1 & Observation & $\begin{array}{l}\text { Progression to stage } \\
\text { IVs and further stage IV }\end{array}$ & No & CR \\
\hline 4 & 3 & OG & $\mathrm{F}$ & 21 & 0 & 1 & 0 & Chemotherapy & Local progression & No & $\mathrm{CR}$ \\
\hline 5 & 3 & OG & $\mathrm{F}$ & 274 & 0 & 0 & 1 & Chemotherapy & Local progression & No & $\mathrm{CR}$ \\
\hline 6 & 2 & OG & M & 373 & 0 & 0 & 1 & Partial resection & Progression to stage IV & No & CR \\
\hline 7 & 1 & OG & M & 42 & 0 & 1 & 0 & Complete resection & No & No & $\mathrm{CR}$ \\
\hline 8 & 2 & HRG & M & 478 & 1 & 1 & 1 & High risk protocol & Progression to stage IV & Yes & Died \\
\hline 9 & 2 & OG & $\mathrm{F}$ & 258 & 0 & 0 & 0 & Observation & No & No & $\mathrm{CR}$ \\
\hline 10 & 3 & OG & M & 477 & 0 & 0 & 1 & Chemotherapy & No & No & $\mathrm{CR}$ \\
\hline 11 & 2 & OG & M & 455 & 0 & 1 & 3 & Chemotherapy & No & No & CR \\
\hline
\end{tabular}

Stage: according to the International Neuroblastoma Staging System; risk group: OG = observation group, HRG = high risk group; Gender: M $=$ male, $\mathrm{F}=$ female; Age: in days at diagnosis; MYCN amp: $1=$ MYCN amplification, $0=$ MYCN single copy; $1 \mathrm{p}$ aberration: $1=1 \mathrm{p}$ aberration, $0=1 \mathrm{p}$ normal; IC (GD2 immunocytology): 1 = positive, $0=$ negative, $3=$ inconclusive, $9=$ not available; last control state $($ according to the International Neuroblastoma Response Criteria): $\mathrm{CR}=$ complete remission. 
association between detection of neuroblastoma mRNA and deletion of $1 \mathrm{p}$ and/or $M Y C N$ amplification. These results can be an indication that patients with qPCR positivity may have more aggressive tumours, also in cases without $1 \mathrm{p}$ aberration or MYCN amplification. Several other factors that may also affect prognosis in neuroblastoma (gene expression signatures [34], the presence or absence of other structural abnormalities [35] and DNA ploidy [36,37]) have been described. Unfortunately these types of data were not available for the patients in our study. In a future study it will be interesting to study the association between qPCR positivity in $\mathrm{BM}$ and these other prognostic factors.

Although we found an association between the detection of neuroblastoma mRNA and unfavourable biological factors $\mathrm{qPCR}$ positivity was not associated with an unfavourable outcome. The high frequency of qPCR positivity in this group of patients and the fact that we did not find an association with outcome may be explained by the very low level of infiltration detected in many patients. It is possible that the detected mRNA originated from circulating and not infiltrating cells. Since it has been demonstrated that extracellular vesicles can also contain tumour specific mRNA $[38,39]$, this may be another possible source of low levels of mRNA in $\mathrm{BM}$ originating from the primary tumour. More aggressive tumours may have more proliferating cells undergoing apoptosis with shedding of tumour RNA. However, this is unknown for neuroblastoma. In this regard it is relevant to mention that in our study RNA was isolated from BM lysed in PAX tubes and not from intact cells. Using this approach also RNA present in microvesicles is isolated. Indeed Hamaoui et al have used the PAX isolation method for the detection of circulating rhodopsin RNA in diabetes patients [40].

When analysing the patients with more than one marker positive $(n=11)$, we found an association with a worse outcome in the whole cohort and in the observation group. This is in line with the results from Corrias et al. 2008 [10]. They detected minimal BM disease in $19 / 145$ patients (13\%), by using GD2 immunocytology, and demonstrated that detection of minimal BM disease was associated with an unfavourable outcome. In our study four out of five relapse patients with more than one marker positive also had minimal disease detected by GD2 immunocytology. This suggests that patients with higher levels of BM infiltration may be at an increased risk for disease progression and require more careful attention on their clinical course. However, further studies on even larger cohorts of patients are needed to verify this.

Because localised patients have a good prognosis, a large number of patients need to be studied to identify a group of patients with an increased risk of relapse. Although we have studied a large cohort of 160 patients, survival analyses may be different when an even larger group of patients is studied.
In conclusion, in this group of patients very few systemic events occur, whereas qPCR positivity in BM is frequent. Therefore, patients with localised disease and qPCR positivity should not be upstaged. qPCR positivity was associated with unfavourable biological factors, suggesting that patients with qPCR positivity in $\mathrm{BM}$ at diagnosis might have more aggressive tumours. The detection of more than one marker was associated with an unfavourable outcome and therefore for these patients a more careful follow-up is advisable. However, much larger studies will be necessary to identify a group of patients with an increased risk of relapse in this cohort with good prognosis.

\section{Acknowledgements}

Financial support: Koningin Wilhelmina Fonds, Dutch Cancer Society (UVA 2010-4738); no further involvement in the study.

The NB2004-HR trial was supported by Deutsche Krebshilfe (\#107712). The authors thank all the pediatric oncologists who participated in the German neuroblastoma trials and especially the following hospitals who contributed bone marrow samples to this analysis:

Department of Pediatric and Adolescent Medicine, University Hospital Aachen (U. Kontny).

Department of Pediatric Oncology, Children's Hospital Augsburg (M. Frühwald).

Department of Pediatric Oncology/Hematology, Charité University Hospital Berlin (A. Eggert).

Clinic for Pediatrics, Helios Klinikum Berlin-Buch (L. Schweigerer).

Gilead Children's Hospital, Bielefeld (N. Jorch).

Department of Pediatric Hematology and Oncology, University Hospital Bonn (D. Dilloo).

Section of Pediatric Oncology, Prof. Hess Children's Hospital, Bremen (A. Pekrun).

Hospital for Children and Adolescents, Chemnitz (A. Hofmann).

Department of Pediatric Oncology, Hematology and Clinical Immunology, University Hospital, Duesseldorf (A. Borkhardt).

Department of Pediatric Hematology and Oncology, Children's Hospital Datteln (T. Wiesel).

Department of Pediatrics and Adolescent Medicine, Municipal Clinics Dortmund (D. Schneider).

Department of Pediatric Hematology and Oncology, University Hospital Dresden (M. Suttorp).

Pediatric Hematology and Oncology, Department of Pediatrics, HELIOS Clinic Erfurt (A. Sauerbrey).

Section of Oncology and Hematology, University Children's Hospital Erlangen (M. Metzler).

Department of Pediatric Hematology and Oncology, University Children's Hospital Frankfurt (T. Klingebiel).

Department of Pediatric Hematology/Oncology, University Medical Center Freiburg (C. Niemeyer). 
Department of Pediatric Hematology and Oncology, University Hospital Giessen (W. Woessmann).

Department of Pediatrics I, University Hospital Göttingen (C. Kramm).

Department of Pediatric Oncology University Children's Hospital Greifswald (H. Lode).

Department of Pediatric Hematology and Oncology, Medical University Hannover (C. Kratz).

Department of Pediatric Hematology and Oncology, University Medical Center Hamburg-Eppendorf (R. Schneppenheim).

Department of Pediatric Oncology, Hematology and Immunology, University of Heidelberg (A. Kulozik).

Department of Pediatric Hematology and Oncology, Medical School Saarland University, Homburg/Saar (N. Graf).

Department of Pediatrics, University Hospital Jena (J. Beck).

Department of Pediatrics, Städtisches Klinikum Karlsruhe (A. Leipold).

Department of Pediatric Hematology and Oncology, Klinikum Nordhessen GmbH, Kassel (M. Nathrath).

Department of Pediatrics, University Hospital Schleswig-Holstein, Kiel (M. Schrappe).

Children's Hospital Kemperhof, Koblenz (R. Ferrari).

Department of Pediatric Oncology and Hematology, University Hospital Leipzig (H. Christiansen).

Pediatric Hematology and Oncology, University Hospital Schleswig-Holstein, Campus Luebeck (M. Lauten).

Department of Pediatric Hematology and Oncology, Otto-von-Guericke-University Magdeburg (P. Vorwerk).

Department of Oncology \& Haemostaseology, Children's Hospital, University Medical Center, Mainz (J. Faber).

Department of Pediatrics, University Children's Hospital Mannheim (M. Dürken).

Department of Pediatrics, Mühlenkreiskliniken, Minden (B. Erdlenbruch).

Department of Pediatric Oncology and Hematology,

Dr von Hauner Children's Hospital, Munich (I. Schmid).

Children's Hospital Medical Center, University of Technology, Munich (S. Burdach).

Department of Pediatric Hematology and Oncology, University Children's Hospital Muenster (H. Juergens).

Cnopf'sche Kinderklinik, Pediatric Hematology and Oncology, Nürnberg (W. Scheurlen).

Department of Pediatrics, Klinikum Oldenburg gGmbH (H. Mueller).

Section of Pediatric Oncology, Department of Pediatrics, University Hospital Regensburg (S. Corbacioglu).

Department of Pediatrics, University Hospital Rostock (C. Classen).
Department of Pediatrics, Helios Clinics Schwerin (C. Guettel).

Department of Pediatrics, Asklepios Clinics St. Augustin (H. Reinhard).

Department of Pediatric Oncology, Hematology and Immunology, Olgahospital Stuttgart (S. Bielack).

Department of Pediatrics, Klinikum Mutterhaus der Borromaeerinnen, Trier (I. Feddersen).

Department of Pediatrics, Oncology/Haematology, University Children's Hospital Tuebingen (R. Handgretinger).

Department of Pediatric Oncology, University Children's Hospital Ulm (K. Debatin).

Department of Pediatric Hematology and Oncology, University Children's Hospital Wuerzburg (P. Schlegel).

\section{Appendix A. Supplementary data}

Supplementary data related to this article can be found at http://dx.doi.org/10.1016/j.ejca.2015.11.007.

\section{Conflict of interest statement}

None declared.

\section{References}

[1] Brodeur GM, Maris JM, Yamashiro DJ, Hogarty MD, White PS. Biology and genetics of human neuroblastomas. J Pediatr Hematol Oncol 1997;19(2):93-101.

[2] Gurney JG, Ross JA, Wall DA, Bleyer WA, Severson RK, Robison LL. Infant cancer in the U.S.: histology-specific incidence and trends, 1973 to 1992. J Pediatr Hematol Oncol 1997; 19(5):428-32.

[3] Haase GM. Metastatic neuroblastoma-does combining several "magic bullets" make a difference? Ann Surg Oncol 1995;2(2): $91-2$.

[4] Cohn SL, Pearson AD, London WB, Monclair T, Ambros PF, Brodeur GM, et al. The International Neuroblastoma Risk Group (INRG) classification system: an INRG Task Force report. J Clin Oncol 2009;27(2):289-97.

[5] Monclair T, Brodeur GM, Ambros PF, Brisse HJ, Cecchetto G Holmes K, et al. The International Neuroblastoma Risk Group (INRG) staging system: an INRG Task Force report. J Clin Oncol 2009;27(2):298-303.

[6] Cheung IY, Barber D, Cheung NK. Detection of microscopic neuroblastoma in marrow by histology, immunocytology, and reverse transcription-PCR of multiple molecular markers. Clin Cancer Res 1998;4(11):2801-5.

[7] Cheung NK, Heller G, Kushner BH, Liu C, Cheung IY. Detection of metastatic neuroblastoma in bone marrow: when is routine marrow histology insensitive? J Clin Oncol 1997;15(8):2807-17.

[8] Beiske K, Burchill SA, Cheung IY, Hiyama E, Seeger RC, Cohn SL, et al. Consensus criteria for sensitive detection of minimal neuroblastoma cells in bone marrow, blood and stem cell preparations by immunocytology and QRT-PCR: recommendations by the International Neuroblastoma Risk Group Task Force. Br J Cancer 2009;100(10):1627-37.

[9] Stutterheim J, Gerritsen A, Zappeij-Kannegieter L, Yalcin B, Dee R, van Noesel MM, et al. Detecting minimal residual disease in neuroblastoma: the superiority of a panel of real-time quantitative PCR markers. Clin Chem 2009;55(7):1316-26. 
[10] Corrias MV, Parodi S, Haupt R, Lacitignola L, Negri F, Sementa AR, et al. Detection of GD2-positive cells in bone marrow samples and survival of patients with localised neuroblastoma. Br J Cancer 2008;98(2):263-9.

[11] Shono K, Tajiri T, Fujii Y, Suita S. Clinical implications of minimal disease in the bone marrow and peripheral blood in neuroblastoma. J Pediatr Surg 2000;35(10):1415-20.

[12] Corrias MV, Haupt R, Carlini B, Cappelli E, Giardino S, Tripodi G, et al. Multiple target molecular monitoring of bone marrow and peripheral blood samples from patients with localized neuroblastoma and healthy donors. Pediatr Blood Cancer 2012;58(1):43-9.

[13] Yanez Y, Grau E, Oltra S, Canete A, Martinez F, Orellana C, et al. Minimal disease detection in peripheral blood and bone marrow from patients with non-metastatic neuroblastoma. J Cancer Res Clin Oncol 2011;137(8):1263-72.

[14] Stutterheim J, Gerritsen A, Zappeij-Kannegieter L, Kleijn I, Dee R, Hooft L, et al. PHOX2B is a novel and specific marker for minimal residual disease testing in neuroblastoma. J Clin Oncol 2008;26(33):5443-9.

[15] Stutterheim J, Zappeij-Kannegieter L, Versteeg R, Caron HN, van der Schoot CE, Tytgat GA. The prognostic value of fast molecular response of marrow disease in patients aged over 1 year with stage 4 neuroblastoma. Eur J Cancer 2011;47(8): 1193-202.

[16] Stutterheim J, Zappeij-Kannegieter L, Ora I, van Sluis PG, Bras J, den Ouden E, et al. Stability of PCR targets for monitoring minimal residual disease in neuroblastoma. J Mol Diagn 2012;14(2):168-75.

[17] Stutterheim J, Ichou FA, den Ouden E, Versteeg R, Caron HN, Tytgat GA, et al. Methylated RASSF1a is the first specific DNA marker for minimal residual disease testing in neuroblastoma. Clin Cancer Res 2012;18(3):808-14.

[18] van Wezel EM, Stutterheim J, Vree F, Zappeij-Kannegieter L, Decarolis B, Hero B, et al. Minimal residual disease detection in autologous stem cell grafts from patients with high risk neuroblastoma. Pediatr Blood Cancer 2015;62(8):1368-73.

[19] van Wezel EM, Zwijnenburg D, Zappeij-Kannegieter L, Bus E, van Noesel MM, Molenaar JJ, et al. Whole-genome sequencing identifies patient-specific DNA minimal residual disease markers in neuroblastoma. J Mol Diagn 2015;17(1):43-52.

[20] Brodeur GM, Seeger RC, Barrett A, Berthold F, Castleberry RP, D'Angio $G$, et al. International criteria for diagnosis, staging, and response to treatment in patients with neuroblastoma. J Clin Oncol 1988;6(12):1874-81.

[21] Ambros PF, Ambros IM. SIOP Europe Neuroblastoma Pathology Biology, Bone Marrow G. Pathology and biology guidelines for resectable and unresectable neuroblastic tumors and bone marrow examination guidelines. Med Pediatr Oncol 2001;37(6): 492-504.

[22] Swerts K, Ambros PF, Brouzes C, Navarro JM, Gross N, Rampling D, et al. Standardization of the immunocytochemical detection of neuroblastoma cells in bone marrow. J Histochem Cytochem 2005;53(12):1433-40.

[23] van der Velden VH, Panzer-Grumayer ER, Cazzaniga G, Flohr T, Sutton R, Schrauder A, et al. Optimization of PCRbased minimal residual disease diagnostics for childhood acute lymphoblastic leukemia in a multi-center setting. Leukemia 2007; 21(4):706-13.

[24] Rubie H, De Bernardi B, Gerrard M, Canete A, Ladenstein R, Couturier J, et al. Excellent outcome with reduced treatment in infants with nonmetastatic and unresectable neuroblastoma without MYCN amplification: results of the prospective INES 99.1. J Clin Oncol 2011;29(4):449-55.
[25] De Bernardi B, Conte M, Mancini A, Donfrancesco A, Alvisi P, Toma P, et al. Localized resectable neuroblastoma: results of the second study of the Italian Cooperative Group for Neuroblastoma. J Clin Oncol 1995;13(4):884-93.

[26] Evans AE, Albo V, D'Angio GJ, Finklestein JZ, Leiken S, Santulli $\mathrm{T}$, et al. Factors influencing survival of children with nonmetastatic neuroblastoma. Cancer 1976;38(2):661-6.

[27] Matthay KK, Sather HN, Seeger RC, Haase GM, Hammond GD. Excellent outcome of stage II neuroblastoma is independent of residual disease and radiation therapy. J Clin Oncol 1989;7(2):236-44.

[28] Kushner BH, Cheung NK, LaQuaglia MP, Ambros PF, Ambros IM, Bonilla MA, et al. International neuroblastoma staging system stage 1 neuroblastoma: a prospective study and literature review. J Clin Oncol 1996;14(7):2174-80.

[29] Navarro S, Amann G, Beiske K, Cullinane CJ, d'Amore ES, Gambini C, et al. Prognostic value of International Neuroblastoma Pathology Classification in localized resectable peripheral neuroblastic tumors: a histopathologic study of localized neuroblastoma European Study Group 94.01 Trial and Protocol. J Clin Oncol 2006;24(4):695-9.

[30] Berthold F, Hero B, Breu H, Christiansen H, Erttmann R, Gnekow A, et al. The recurrence patterns of stages I, II and III neuroblastoma: experience with 77 relapsing patients. Ann Oncol 1996;7(2):183-7.

[31] Hero B, Simon T, Spitz R, Ernestus K, Gnekow AK, ScheelWalter HG, et al. Localized infant neuroblastomas often show spontaneous regression: results of the prospective trials NB95-S and NB97. J Clin Oncol 2008;26(9):1504-10.

[32] Caron H, van Sluis P, de Kraker J, Bokkerink J, Egeler M, Laureys $\mathrm{G}$, et al. Allelic loss of chromosome $1 \mathrm{p}$ as a predictor of unfavorable outcome in patients with neuroblastoma. N Engl J Med 1996;334(4):225-30.

[33] Brodeur GM, Seeger RC, Schwab M, Varmus HE, Bishop JM. Amplification of $\mathrm{N}$-myc in untreated human neuroblastomas correlates with advanced disease stage. Science 1984;224(4653): 1121-4.

[34] Vermeulen J, De Preter K, Naranjo A, Vercruysse L, Van Roy N, Hellemans J, et al. Predicting outcomes for children with neuroblastoma using a multigene-expression signature: a retrospective SIOPEN/COG/GPOH study. Lancet Oncol 2009;10(7):663-71.

[35] Schleiermacher G, Janoueix-Lerosey I, Ribeiro A, Klijanienko J, Couturier J, Pierron G, et al. Accumulation of segmental alterations determines progression in neuroblastoma. J Clin Oncol 2010;28(19):3122-30.

[36] Look AT, Hayes FA, Nitschke R, McWilliams NB, Green AA. Cellular DNA content as a predictor of response to chemotherapy in infants with unresectable neuroblastoma. N Engl J Med 1984; 311(4):231-5.

[37] Look AT, Hayes FA, Shuster JJ, Douglass EC, Castleberry RP, Bowman LC, et al. Clinical relevance of tumor cell ploidy and Nmyc gene amplification in childhood neuroblastoma: a Pediatric Oncology Group study. J Clin Oncol 1991;9(4):581-91.

[38] Skog J, Wurdinger T, van Rijn S, Meijer DH, Gainche L, SenaEsteves M, et al. Glioblastoma microvesicles transport RNA and proteins that promote tumour growth and provide diagnostic biomarkers. Nat Cell Biol 2008;10(12):1470-6.

[39] Hong BS, Cho JH, Kim H, Choi EJ, Rho S, Kim J, et al. Colorectal cancer cell-derived microvesicles are enriched in cell cyclerelated mRNAs that promote proliferation of endothelial cells. BMC Genomics 2009;10:556.

[40] Hamaoui K, Butt A, Powrie J, Swaminathan R. Concentration of circulating rhodopsin mRNA in diabetic retinopathy. Clin Chem 2004;50(11):2152-5. 